\title{
MULTIPLE-BALLOON-KYMOGRAPH RECORDING OF INTESTINAL MOTILITY IN MAN WITH OBSERVATIONS ON THE COR- RELATION OF THE TRACING PATTERNS WITH BARIUM MOVEMENTS ${ }^{1}$
}

\author{
By WILLIAM P. CHAPMAN and WILLIAM L. PALAZZO With ThE TECHNICAL \\ ASSISTANCE OF AUDREY TAYLOR AND WARREN PROUDFOOT \\ (From the Medical Services and Department of Radiology, Massachusetts General Hospital: \\ and the Department of Medicine and Radiology, Hariard Medical School, \\ Boston, Massachusetts)
}

(Received for publication March 2, 1949)

The balloon water manometer system has long been employed in animals and in man as a means of recording graphically the motility of the alimentary tract $(1,2)$. As others have done, we have used this method to study the behavior of adjacent segments of the small intestine in man under control conditions and in response to drugs and placebos $(3,4)$. The purpose of this communication is to describe the recording procedure and the evaluation of the tracing patterns. The results of the drug and placebo studies are to be reported elsewhere.

Certain drawbacks to the use of the balloon water manometer system have been presented by Quigley (5). He has pointed out that this method necessitates using a large volume/pressure coefficient which does not maintain a linear relationship. The pressure, moreover, registered by the balloon varies depending on its changing shape and on the degree of patency of the intestinal lumen. These objections did not primarily concern us as we were interested in qualitative and relative quantitative changes in motility rather than in absolute measurements of intraluminal pressures.

Various workers have described graphic records of motility in terms of their non-propulsive and propulsive character (6-9). Adler, Atkinson and Ivy (6) observed that in the colon of patients with colostomies low, relatively rapid wave patterns were non-propulsive while high, sustained contractions were associated with the forward movement of the intestinal contents provided adequate coordination existed between bowel segments. Abbott and Pendergrass (7) felt that a

1 This study was supported by grants from Josiah $\mathrm{H}$. Macy, Jr., Foundation, New York; Hoffmann-LaRoche, Inc., Nutley, New Jersey ; and G. D. Searle and Company, Chicago, Illinois. clear-cut distinction could not always be made between peristaltic contractions appearing as large waves and non-propulsive, segmental contractions appearing as smaller waves. Later, Ingelfinger and Abbott (8) in combined balloon recording and barium studies obtained evidence which further suggested that the small rapid wave patterns represented rhythmic or segmental contractions and the larger waves, peristaltic contractions. We have repeated the observations of Abbott and his associates, using the multiple-balloon recording system and noting at the same time the relationship between the wave patterns and the movement of barium.

\section{Description of the recording apparatus and the methods of assessing the graphic records}

\section{A. Apparatus}

A photograph of the recording apparatus is shown in Figure 1.2 The five water manometers are attached next to the drum on the right so that each ink-writer moves along a vertical line, one above the other. The upper four manometers connect to the four-lumen tube, and the fifth or lowest manometer, to the pneumatic respiratory cuff. As shown in the middle and left-hand sections of Figure 2, the location of the tracing on the kymograph paper for each balloon is as follows: the top or No. 1 tracing for the tip or distally located balloon; No. 2 tracing for the next proximal balloon; No. 3 tracing for the third balloon from the tip of the tube; and the No. 4 tracing for the proximal balloon. Time is indicated in minutes at the bottom of the recording paper.

\footnotetext{
2 The floats were constructed of lucite with slightly concave-shaped walls. The monel metal universal joint attached to the tip of the float prevented it from sticking.
} 


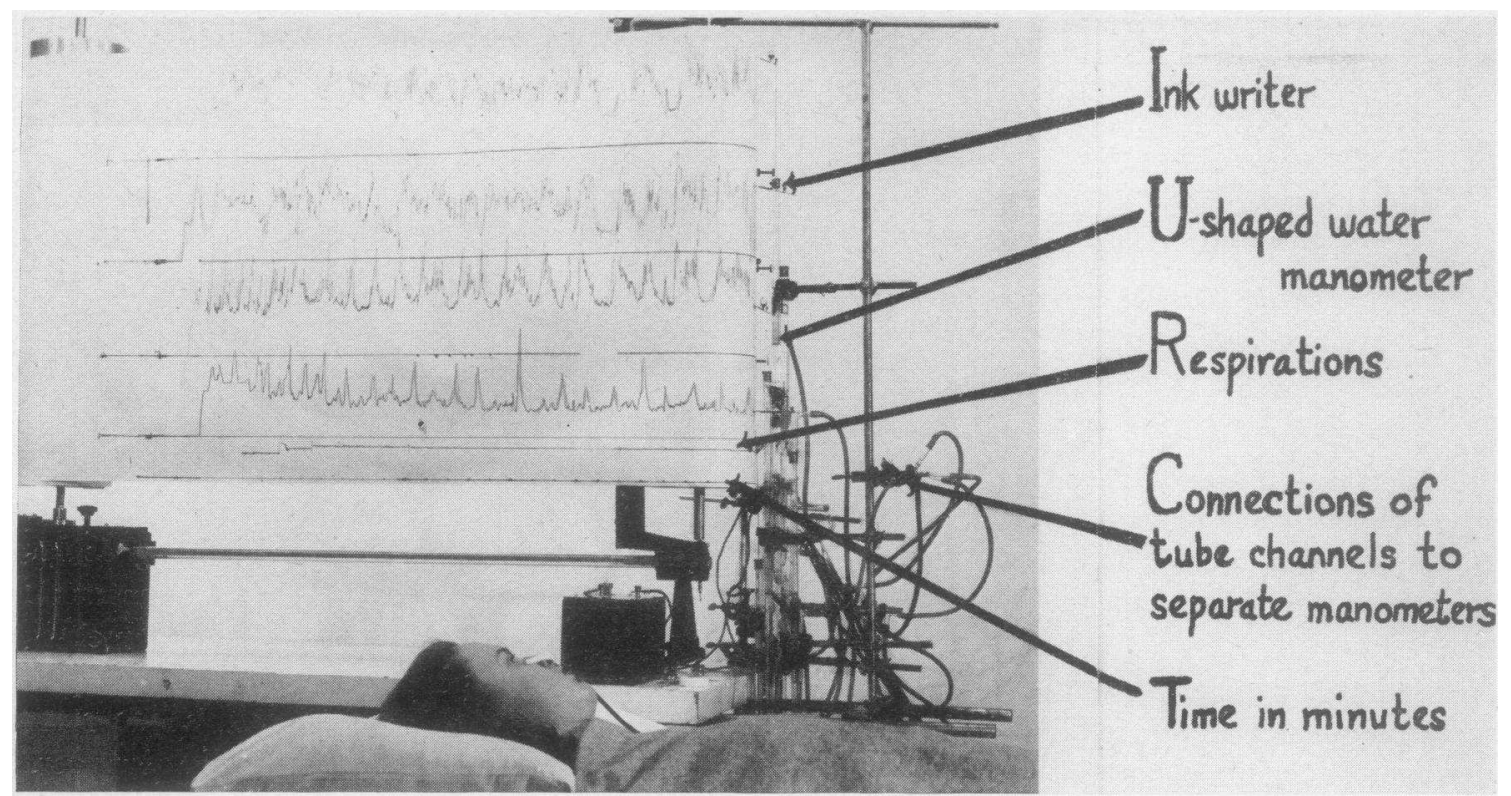

Fig. 1. Photograph of Apparatus Showing Kymograph, U-Shaped Water Manometers with Ink-Writing Pens, Baselines, Respiratory Tracing, and One-Minute Time Intervals at the Bottom of the Tracing

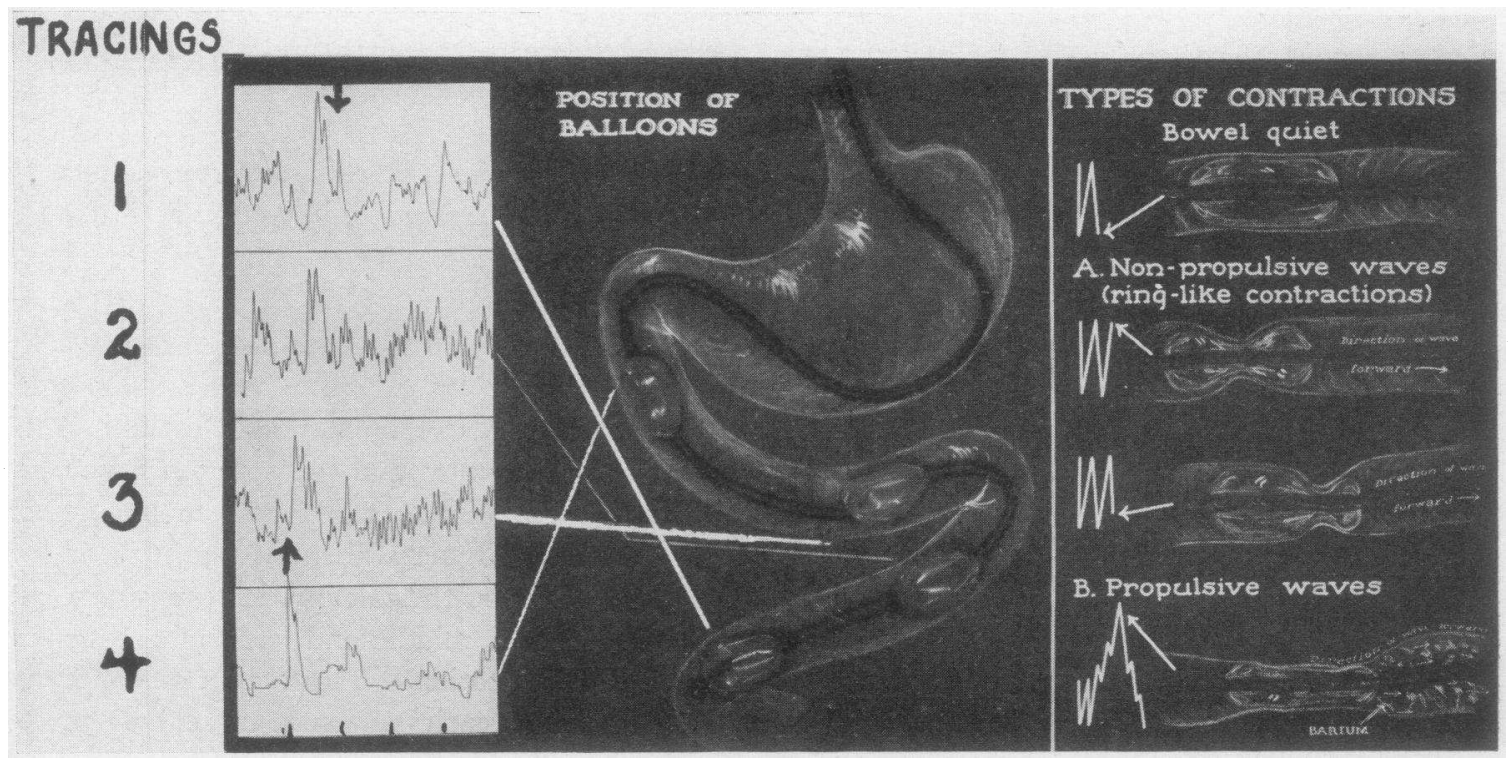

Fig. 2. Photograph Showing location of Tracing for Each Balloon on Graphic Record and IllustraTION OF TYPES OF CONTRACTIONS

In the center drawing is shown the position of the balloons in the upper small intestine. The lines leading to the five-minute graphic record on the left indicate the positions for each balloon tracing. On the right are illustrated contractions regarded as typical of propulsive or peristaltic waves and non-propulsive or ring-like waves (segmental contractions). The arrows on the right point to the position of the ink-writers at the instant the particular phase of intestinal activity was observed fluoroscopically. 


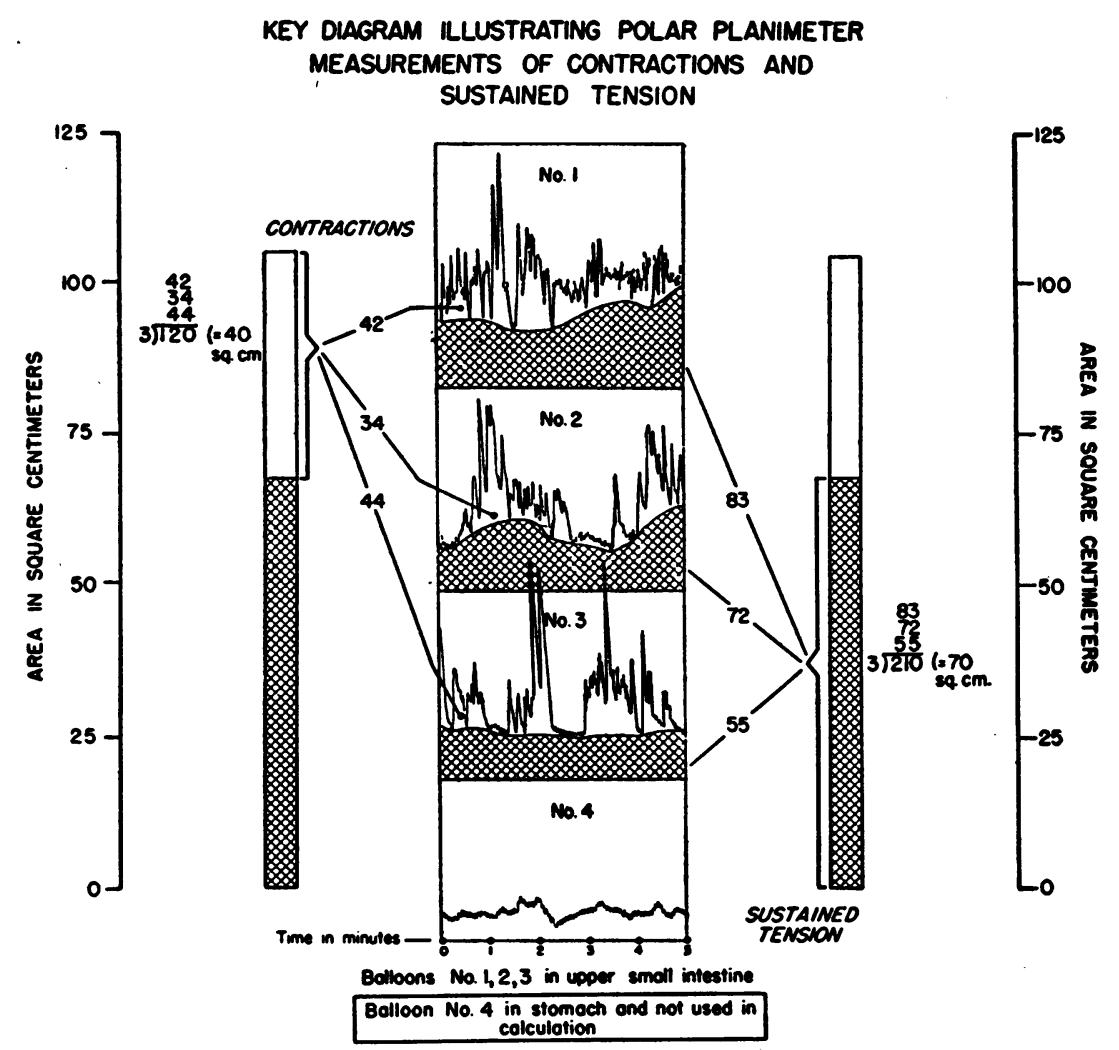

FIG. 3

This figure illustrates the method of measuring the surface areas underneath the three intestinal tracings. The cross-hatched area beneath the drawn black line represents the sustained tension or "tone" area. The white area above the drawn black line and bordered by the contraction waves represents the contraction area. The mean of the sum of the surface area values for contractions is graphed in sq. $\mathrm{cm}$. at the upper part of the left-hand scale. The mean of the sum of the surface area values for "tone" or sustained tension is graphed in sq. $\mathrm{cm}$. at the lower portion of the right-hand scale. Each surface area is measured by tracing the area border with a polar planimeter.

The four-lumen tube is size No. $18 .^{3}$ The balloons, spaced at four-inch intervals, are wound on the tube allowing a uniform length of 2.5 inches and with just enough slack so that 20 to $25 \mathrm{cc}$. of air inflation produces only a beginning elevation of the ink-writer when the balloons are lying on a flat surface. The sensitivity of the air conduction system was standardized by applying a uniform pressure suddenly to the mid-portion of each balloon connected to the manometer and filled with $50 \mathrm{cc}$. of air and then noting the shape of the curve made on the recording paper travelling at a rapid speed. When the tube is in position in the intestine for recording, each balloon is filled uni-

\footnotetext{
${ }^{3}$ The four-lumen tube was manufactured by G. P. Pilling and Son Company, Philadelphia, Pennsylvania.
}

formly with $20 \mathrm{cc}$. of air through a side T-tube connection. This amount of air never causes pain in the small intestine or colon and is sufficient to record all activity except for the very marked "spasms" or sudden striking increase in "tone" which is occasionally seen following the injection of morphine.

\section{B. Method of assessing the graphic records}

\section{Visual inspection}

Qualitative changes in contractions can only be evaluated by visual inspection of the records. As shown in the right-hand section of Figure 2 and as will be discussed in detail later, propulsive and non-propulsive (segmental or ring-like) con- 


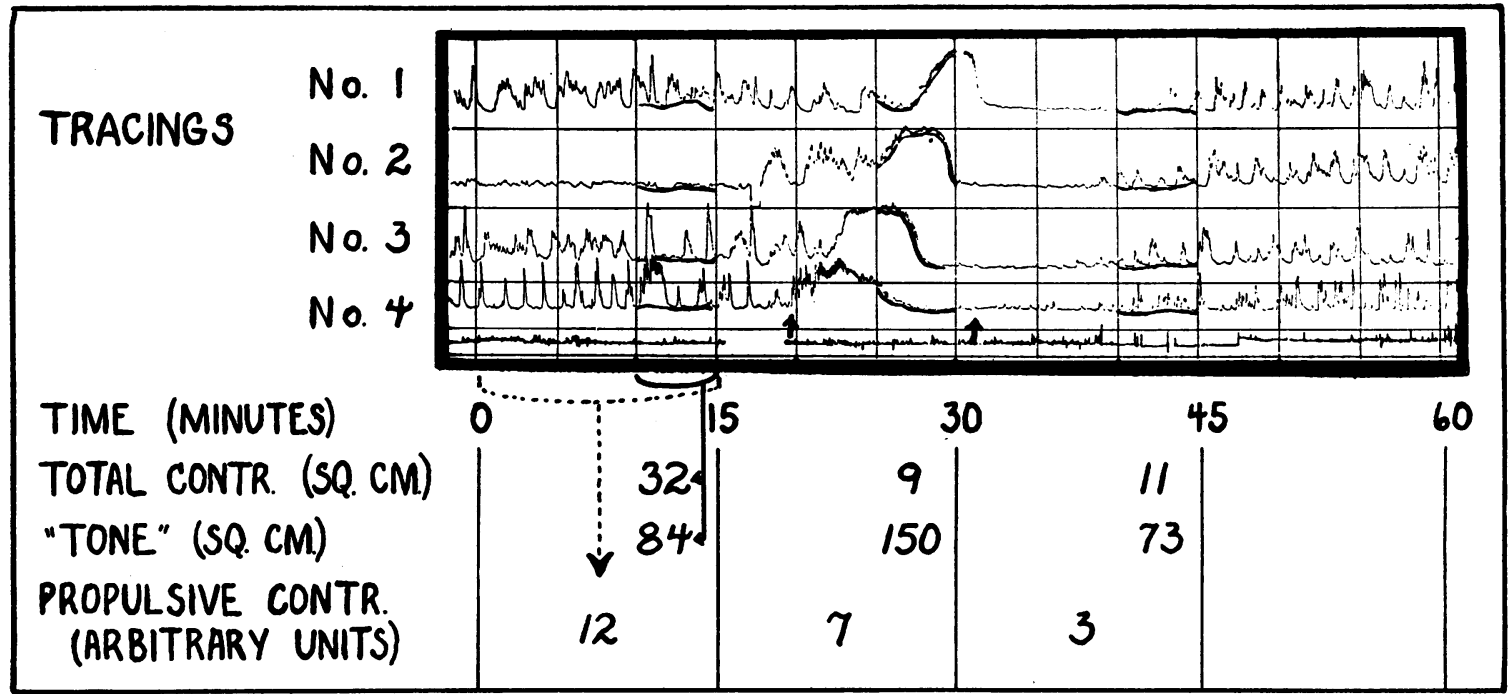

Fig. 4. A Graphic Record of Intestinal Motility Showing Marked Increase in "Tone" Value and Decrease in Value for total Contractions During "Spasms" at 25-30 Minute Period

The sq. cm. values for total contractions and "tone" were measured for five-minute periods per 15-minute intervals. The values for propulsive contractions represent the average levels per 15-minute period, were expressed in arbitrary units and were obtained by the visual inspection method.

tractions could usually be distinguished as well as "spasms" (noted between the arrows in (Figure 4). Tall waves with a broad base covering a time interval up to two minutes appeared to represent peristaltic contractions. Low waves of more rapid frequency appeared to represent segmental, ring-like or non-propulsive contractions. "Spasms" were associated with an elevation of the baseline usually to the upper limits of the previous contractions and with superimposed small, frequent, segmental types of contractions. In some individuals breathing movements might be superimposed on the balloon tracings particularly during "spasms" and propulsive movements. The respiratory movements were usually of a different frequency and could be easily identified. Occasionally they complicated the interpretation of segmental contractions.

Quantitative variations in contractions could usually be approximated by determining their frequency, duration and amplitude per unit of time (Figure 4). "Tone," to be defined later, was more difficult to assess by visual inspection, though measurements with a centimeter ruler of the average distance between the resting level of contractions and the baseline of the tracing per fiveminute interval revealed changes of more than a slight degree.
2. Polar planimeter measurements of surface areas representing contractions and "tone"

Surface area measurements did not permit a differentiation between propulsive and non-propulsive waves but did make possible a more objective evaluation of relative changes in contractions as well as of fluctuations in "tone" than could be determined by visual inspection. "Tone" was defined as the sustained tension of the intestinal wall present during the resting phases of propulsive and segmental or non-propulsive contractions. The surface area representing "tone" was that portion of the graphic tracing below a line drawn just beneath the points of the tracing representing the quiescent phases of the contractions. The surface area above this line and inside the borders of the contractions was the portion of the tracing which represented contractile activity. Figure 3 shows how the line separating contractions and "tone" was drawn and illustrates the calculation of the mean of the sum of the values for these two components of motility over a five-minute period. ${ }^{4}$ The mean of the sum of the surface area values for

4 The area measured is the area under a pressure curve for a five-minute interval, the height of the curve being proportional to the average pressure during that interval. The polar planimeter measures the area simply by tracing along the area border. 
each tracing expressed in sq. $\mathrm{cm}$. is shown graphically by the scale at the sides of the illustration. It will be noted that balloon No. 4 was not included in the calculation for small intestinal motility as it was located in the stomach. In most experiments we have found it sufficient to make the surface area calculations for five-minute periods at uniform intervals of 15 minutes as indicated in Figure 4. The surface area calculation at the 25-30 minute period shows that during intervals of "spasm" there is a striking increase in "tone" and very little contractile activity. An alternative method of drawing the line separating contractions and "tone" was tried by dividing the two components by a horizontal line touching the base of the lowest contraction for one-minute or for five-minute intervals. This alternative method appeared to give exaggerated contraction values for "spasms" or for sustained contractions lasting more than three minutes and was discarded in favor of the procedure described in the key diagram in Figure 3. One slight source of error in making these measurements was inherent in our kymograph method. The collection of the recording paper by the left-hand drum caused a slow, progressive increase in the drum diameter and, hence, an increase in the speed of movement of the tracing per revolution. As this progressive increase in the speed of travel of the paper introduced an error in surface area calculations at the end of a four-hour recording period as compared to the first hour of usually not more than 4 per cent, which was no greater than the error inherent in measuring any one surface area, it seemed unnecessary to correct for this technical defect.

\section{METHOD}

\section{A. Correlation of barium movements with simul- taneous graphic recording of contractions}

Three to eight observations lasting from 10 to 15 minutes were carried out in seven healthy fasting adults. After either two or three balloons had entered the small intestine, the subject was given a small drink of barium. When the barium distributed itself around the balloons, each balloon was inflated with $20 \mathrm{cc}$. of air and the recording started. By fluoroscopy it was possible to observe the changing position of the barium around the balloons and the outline of each balloon with sufficient accuracy to note its changing contour during contractions. A forward movement of barium was arbitrarily regarded as taking place when it moved forward a minimum distance of 2 inches. Whenever this occurred, the effect of this contraction on the graphic recording was noted. Notations were also made of the changing

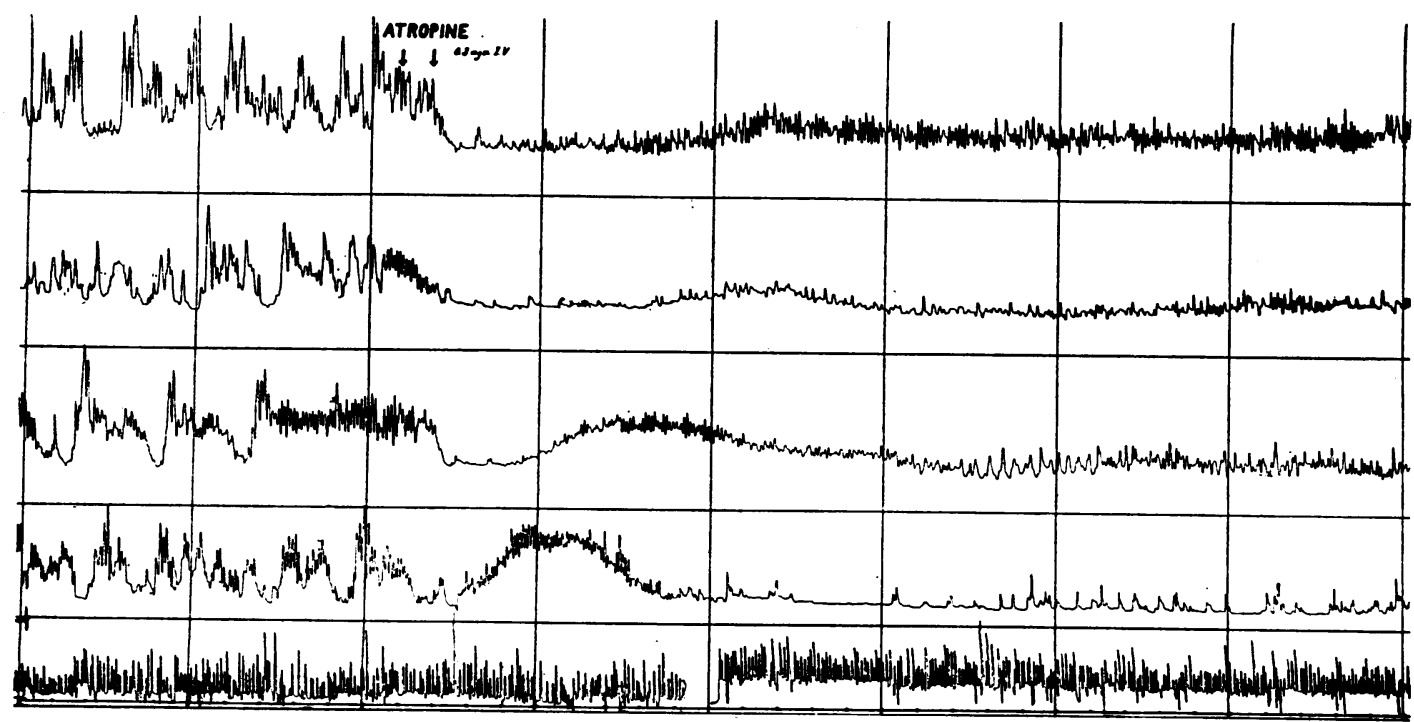

Fig. 5. The Effect of the Intravenous Admin istration of Atropine, 0.3 mgm., on Adjacent Segments of the UpPer SMall Intestine

Balloon positions: upper small intestine.

This record shows a typical decrease in contractions and bowel relaxation occurring one to two minutes after the intravenous injection of atropine. About one minute later a temporary elevation in "tone" occurred which is most pronounced in tracings Nos. 3 and 4. 


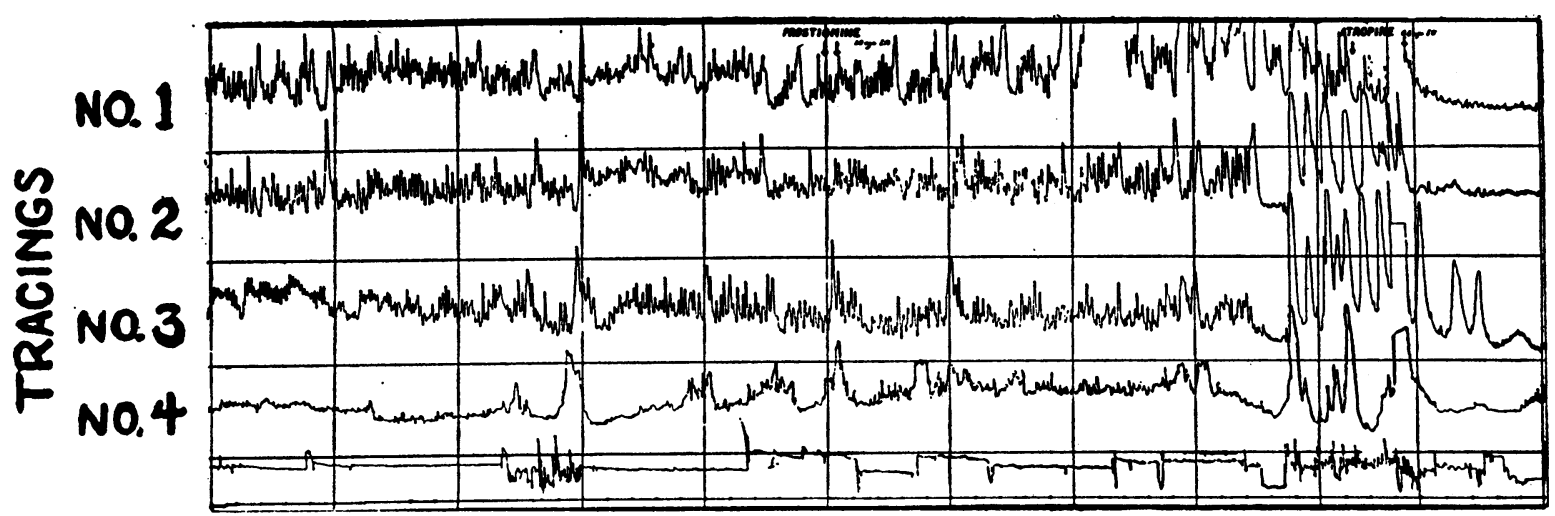

Fig. 6. Increased Contractions of the Jejunum Associated with Severe Abdominal Pain following the Intramuscular Injection of 1.0 mgm. of Prostigmine

The No. 4 tracing represents the most proximal area of the jejunum studied. Activity in the more distal areas is represented in succession by tracings Nos. 3, 2, and 1, respectively. Time is indicated at five-minute intervals by the vertical lines. The figure shows that the onset of the high sustained waves occurred 18 minutes after the injection of prostigmine and was associated with severe, generalized abdominal pain. Atropine, $0.6 \mathrm{mgm}$., given intramuscularly five minutes after the onset of pain abolished contractions with complete relief of pain. It can be seen that, as the upstroke of the high, sustained waves occurred, the next distal tracing showed relative inactivity.

contour of the balloons with or without a movement of barium.

\section{B. Effect of drugs on the motility pattern}

In order to show the changes taking place in the motility pattern following the administration of drugs, two records are presented, one showing the action of intravenous atropine, $0.3 \mathrm{mgm}$., the other showing the production of severe pain following the intramuscular administration of $1.0 \mathrm{mgm}$. of prostigmine. Both subjects were patients with essential hypertension who were in a fasting state during the recording with the balloons in the upper small intestine. Atropine was given following a 30 -minute control period though only the last $10 \mathrm{~min}$ utes of this period is shown in Figure 5. Prostigmine was given following a 25 -minute control period (Figure 6).

\section{RESULTS}

A. Correlation of barium movements with simultaneous graphic recording of contractions

The results of the correlation of the forward movement of barium and the simultaneous graphic recordings of motility are shown in Table $I$. Forty-five correlations were made in the seven subjects. In 35 instances, the forward movement of the barium occurred simultaneously with a slow, high, sustained contraction. In eight instances, a sustained contraction occurred in the absence of a forward movement of barium. On two occasions, failure to note a forward movement of barium during a high, sustained contraction may have been due to the presence of an insufficient amount of barium.

TABLE I

Correlation of graphic waves and barium movement during sustained, high contractions

\begin{tabular}{|c|c|c|c|c|c|}
\hline \multirow[t]{2}{*}{$\begin{array}{l}\text { Subject } \\
\text { number }\end{array}$} & \multirow{2}{*}{$\begin{array}{c}\text { Number } \\
\text { of } \\
\text { obser- } \\
\text { vations }\end{array}$} & \multicolumn{3}{|c|}{$\begin{array}{c}\text { Forward movement } \\
\text { of barium occurring } \\
\text { simultaneously with } \\
\text { a high, sustained } \\
\text { contraction }\end{array}$} & \multirow[t]{2}{*}{ Comment } \\
\hline & & Yes & No & $\underset{\text { tionable }}{\text { Ques- }}$ & \\
\hline 1 & 6 & 5 & 1 & 0 & \\
\hline 2 & 8 & 6 & $2 *$ & 0 & \\
\hline 3 & 3 & 0 & 1 & 2 & $\begin{array}{l}\text { No clear-cut high, sus- } \\
\text { tained contractions } \\
\text { were observed on trac- } \\
\text { ing }\end{array}$ \\
\hline 4 & 7 & 7 & 0 & 0 & $\begin{array}{l}\text { In one instance, three } \\
\text { successive, high, sus- } \\
\text { tained contractions oc- } \\
\text { curred, accompanied by } \\
\text { forward movement of } \\
\text { barium past the bal- } \\
\text { loons registering these } \\
\text { contractions }\end{array}$ \\
\hline 5 & 7 & 5 & 2 & 0 & \\
\hline 6 & 6 & 5 & 1 & 0 & \\
\hline 7 & 8 & 7 & 1 & 0 & \\
\hline Totals & 45 & 35 & 8 & 2 & \\
\hline
\end{tabular}

*Question of sufficient barium present to be propelled. 
In two other instances, when high, sustained contractions occurred, the forward movement of barium was questionable. In subject No. 4 , as barium on one occasion moved by the three distal balloons large, sustained contractions were registered in succession by those balloons indicated between the arrow points in the tracings at the left of Figure 2. A reversal of the barium movement indicating antiperistalsis was not observed.

Except for subject No. 3, who showed practically no contractions either by fluoroscopy or by the graphic record, the tracings in the remaining subjects showed low amplitude waves varying in frequency from one to ten per minute. These small waves were invariably associated with ringlike contractions always running in a forward direction over the balloons. During these ring-like constrictions it was possible that the balloon and barium moved slightly but barium was never propelled forward.

Drawings of the changing shape of the balloons seen fluoroscopically are shown at the right of Figure 2. When the intestine was quiet, the balloon appeared inflated and the ink-writer maintained a resting position. When the ring-like contraction reached the mid-portion of the balloon, the ink-writer rose to the high point of the contraction wave. As the contraction ring proceeded toward the distal end of the balloon, the ink-writer fell toward its previous resting location on the graphic record. During the high, sustained contractions, the entire balloon became partially or completely obliterated and frequently moved forward. Then, simultaneously with the downstroke of the ink-writer, the balloon moved back toward its previous position. The duration of a small, segmental or ring-like contraction varied from five to 10 seconds. Sustained contractions lasting for longer than two minutes, did not appear during our fluoroscopic observations. We were, therefore, unable to say whether such longer lasting contractions represented propulsive or nonpropulsive movements. Additional evidence that the high, sustained waves shown in Figure 2 indicated propulsive contractions has been noted in other experiments. During the upstroke of these contractions, several subjects reported a downward tug of the tube in the nose.
B. Motility relaxing action of intravenous atropine; the production of intestinal pain following prostigmine administration with its subsequent relief following atropine injection

Figure 5 shows the typical disappearance of propulsive contractions and a lęss striking decrease in non-propulsive activity and "tone" within one minute after the intravenous injection of 0.3 mgm. of atropine. The temporary elevation in "tone" noted one minute later has been observed not uncommonly during the first 10 or 15 minutes after the intravenous administration of atropine (10). The decrease in contractions and "tone" persisted for four hours after the injection in this subject.

Figure 6 shows an increase in contractions following the intramuscular administration of prostigmine, $1.0 \mathrm{mgm}$. Eighteen minutes after the injection the subject, a patient with essential hypertension, experienced very severe, generalized, crampy abdominal pain which was associated with very high, sustained contractions recorded from the upper small intestine. It will be noted that there was a tendency for the high, sustained contractions (propulsive) to pass over the balloons in a forward direction. If the marked elevation of the tracings during the attack of pain had been due to increased abdominal pressure, the upstrokes and downstrokes of the waves noted in Figure 6 would have occurred simultaneously. Instead, the upstroke occurred first in the proximal and then in the more distally located balloons. Five minutes after the onset of pain, atropine $0.6 \mathrm{mgm}$. was injected intravenously over a two- to three-minute period with almost immediate decrease in contractions and with complete relief of pain.

\section{CONCLUSIONS}

A description of the apparatus, the method of assessing the motility patterns and the results of correlating the tracings with barium movements have been presented. As previously mentioned, numerous authors have utilized these various techniques in the investigation of the gastrointestinal tract in animals and in the human. However, because an accurate interpretation of our records required specific information regarding the particular techniques and procedures used, we have reported these facts in some detail. 
The four-channelled recording permitted a more complete study of gastrointestinal motility than was possible by the use of a single balloon. For example, it was possible to show the direction of movement of propulsive contractions as well as of "spasms" or temporary sudden elevations in "tone" (Figures 2, 4 and 6). With greater spacing between balloons it would have been possible to study the difference in behavior of more widely separated areas of the alimentary tract. Our observations on the relationship of motor activity in adjacent bowel segments under control conditions and in response to drugs are to be reported elsewhere. The utilization of the multiple recording method, on the other hand, necessitated taking certain additional precautions. Important among them was the care taken in the calibration of the balloons so that each one registered comparable excursions of the ink-writer from the same application of pressure. Some individuals found that the swallowing of four rather than of one balloon added to the discomfort of the procedure. While at first the variability of the motility pattern in different balloons made the analysis of the record as a whole difficult, this problem was in large part resolved in terms of figures of the measurements of surface areas subtended by the tracings.

Our findings showing that small, rapid waves were never associated with the forward movement of barium seemed to justify the assumption that such tracings represent non-propulsive contractions. While the correlation between high, sustained contractions and the propulsion of barium was less striking, the evidence strongly supported the view that such wave patterns represent an effort on the part of the bowel to transport its contents. During the course of our studies, tracing patterns have frequently been seen in which the shape of the curves appeared to be a mixture of non-propulsive and propulsive contractions. Since such tracings were not studied in correlation with the movement of barium, we are unable to be more specific regarding their nature. These interpretations of graphic records appear to substantiate the observations of the workers mentioned previously. Undoubtedly more satisfactory graphic representation of motility will be obtained when suitable techniques are devised which can provide reliable data concerning the relationship of intraluminal pressures over a series of adjacent areas along the intestine.

\section{SUMMARY}

1. A method of multiple-balloon recording of intestinal motility and the techniques of evaluating the graphic records have been presented.

2. Polar planimeter measurements of surface areas representing total contractions and "tone" made it possible to express the variations in motility in terms of figures and to obtain a more objective evaluation of these changes than was possible by visual inspection of the records.

3. A correlation of the tracing patterns with barium movements revealed that low, rapid waves were non-propulsive. While the high, sustained tracing patterns were more difficult to interpret, the evidence obtained strongly suggested that they represented propulsive contractions.

4. One graphic record has been presented showing the changes in the multiple-balloon tracings during pain following the intramuscular injection of prostigmine and its subsequent relief by the intravenous injection of atropine. Another graphic record has been included to show the action of an intravenous injection of atropine alone on motility.

\section{ACKNOWLEDGMENTS}

The authors wish to acknowledge permission from W. G. Saunders Company for the use of the prostigmine chart in Figure 6. The lucite floats used in this study were constructed by Mr. Fred Christensen, Mechanics Shop, Harvard Medical School, and were the type used by the Departments of Physiology and Pharmacology.

\section{BIBLIOGRAPHY}

1. Alvarez, W. C., An Introduction to Gastro-Enterology. Paul B. Hoeber, Inc., New York, 394, 1940.

2. Ganter, G., Ueber die Peristaltik des Menschlichen Dunndarms. Munchen. Med. Wchneschr., 1921, 68, 1447.

3. Templeton, R. D., and Bollens, W. F., Attempts to secure objective methods of studying mild anaphylaxis. J. Lab. \& Clin. Med., 1930, 15, 585.

4. Quigley, J. P., and Solomon, E. I., Action of insulin on motility of the gastro-intestinal tract. Am. J. Physiol., 1930, 91, 488.

5. Glasser, Otto, Medical Physics, section on digestive tract by Quigley, J. P., The Year Book Publishers, Inc., Chicago, III., 310, 1944. 
6. Adler, H. F., Atkinson, A. J., and Ivy, A. C., A study of the motility of the human colon: an explanation of the dysynergia of the colon, or of the "unstable colon." Am. J. Digest. Dis., 1941, 8, 197.

7. Abbott, W. O., and Pendergrass, E. P., Intubation studies of the human small intestine, V. The motor effects of single clinical doses of morphine sulphate in normal subjects. Am. J. Roentgenol., 1936, 35, 289.
8. Ingelfinger, F. J., and Abbott, W. O., Intubation studies of the human small intestine, XX. The diagnostic significance of motor disturbances. Am. J. Digest. Dis., 1940, 7, 468.

9. Plant, O. H., The effect of carminative volatile oils on the muscular movements of the intestine. J. Pharm. \& Exper. Therapy., 1920, 16, 311.

10. Chapman, W. P., Unpublished data. 